\title{
Tri Ubaya: Alih Wahana dari Pertunjukan Wayang Menjadi Karawitan
}

\author{
Sunyata ${ }^{1}$ \\ Jurusan Karawitan, Fakultas Seni Pertunjukan, Institut Seni Indonesia Yogyakarta
}

\begin{abstract}
Tri Ubaya: Intermediality From Wayang to Karawitan Performance. Karya ini merupakan alih wahana dari pertunjukan wayang kulit menjadi pertunjukan karawitan. Cerita wayang lakon Alap-alapan Kunthi saya alih wahanakan menjadi pertunjukan karawitan. Cerita ini dipilih karena di dalamnya terdapat peristiwa yang dahsyat, ucapan Dewi Gendari yang berisi tiga janji (tri ubaya) menjadi cikal bakal perang Barata Yudha. Komposisi karawitan ini mengalihwahanakan suatu tokoh, suasana, karakter, dan peristiwa dalam pertunjukan wayang menjadi komposisi karawitan.
\end{abstract}

Key words: alih wahana, barata yuda, wayang, karawitan.

\section{Pendahuluan}

Alih wahana merupakan pengubahan dari satu jenis kesenian ke jenis kesenian lain. Alih wahana mencakup kegiatan penerjemahan, penyaduran,dan pemindahan dari satu jenis kesenian ke jenis kesenian yang lain (Damono, 2011: 1). Berdasarkan definisi ini, pertunjukan wayang sebenarnya juga bentuk alih wahana dari teks tulis dan lisan mengenai cerita Ramayana, Mahabarata, dan mitos lokal menjadi bentuk pertunjukan wayang.

Alih wahana dari pertunjukan wayang menjadi pertunjukan karawitan belum banyak dilakukan oleh para seniman. Sejauh ini karawitan menjadi bagian atau pendukung pertunjukan wayang. Saya tertantang untuk mencoba mengalihwanakan cerita wayang menjadi pertunjukan karawitan.

Cerita Tri Ubaya dipilih karena cerita ini memiliki andil yang besar akan terjadinya peristiwa Barata Yudha yang menjadi sumber cerita utama dalam pertunjukan wayang. Cerita ini dialihwahanakan dari lakon Sayembara Pilih atau Alapalapan Kunthi. Setelah dialih-wahanakan terjadi perubahan peran tokoh sentral. Pada lakon Alapalapan Kunthi tentu yang menjadi tokoh sentral adalah Kunthi. Pada lakon Tri Ubaya, yang menjadi tokoh sentral adalah Gendari.

\section{Kunthi Pilih dalam Wahana Wayang}

Pertunjukan wayang lakon Kunthi Pilih diawali dari persiapan seribu raja dari berbagai negara (sewu negara) berkumpul di Negara Madyantara di bawah kekuasaan Kurumbadewa yang akan berangkat ke Negara Mandura untuk mengikuti sayembara pilih. Setelah bermufakat mereka berangkat bersama-sama ke Mandura. Dalam hari yang sama, putra raja Mandaraka bernama Narasoma sedang berada di perjalanan dalam keadaan hati gelisah karena oleh ayahnya di suruh pergi meninggalkan kerajaan. Di tengah perjalanan ia mendengar berita bahwa di Negara Mandura ada sayembara pilih untuk dijadikan pendamping hidup Kunthi. Mendengar berita tersebut, Narasoma berangkat ke Mandura untuk mengikuti sayembara pilih tersebut.

Sesuai dengan hari yang ditentukan, di Negara Mandura sedang mempersiapkan upacara sayembara dan tidak lama kemudian datang seribu raja dari kerajaan Madyantara dan Narasoma dari Mandaraka. Sayembara segera dimulai dan yang mendapat kesempatan dipilih pertama adalah seribu raja yang dipimpin oleh Kurumbadewa. Tidak satupun raja dari sewu nagari dipilih Kunthi. Kesempatan berikutnya adalah Narasoma. Ketika melihat ketampanan Narasoma, hati Kunthi bergetar. Ia kemudian menyatakan pilihannya kepada Narasoma yang juga disetujui oleh semua pihak di kerajaan Mandura. Kunthi diajak pulang ke Mandaraka.

Dalam perjalanan pulang, Narasoma dan Kunthi bertemu dengan Pandu yang sedianya ingin mengikuti sayembara tetapi sudah terlambat. Narasoma mengatakan kepada Pandu

1 Alamat korespondensi: Prodi Seni Karawitan ISI Yogyakarta. Jalan Parangtritis KM. 6,5 Sewon, Yogyakarta 55001. Telepon: +6281578941715. E-mail: nyatapengrawit@isi.ac.id 
bahwa sayembara telah selesai dan dirinyalah yang menang. Akan tetapi kalau Pandu mau, Kunthi akan dijadikan sayembara lagi. Ia berjanji kepada Pandu kalau bisa mengalahkannya Pandu boleh mencintai Kunthi dan membawanya pulang. Pandu tidak tinggal diam. Ia sanggup dengan aturan Narasoma. Pandu bisa memenangkan perang, maka Narasoma menyerahkan Kunthi pada Pandu. Selain menyerahkan Kunthi, Narasoma juga menyerahkan Madrim, adik perempuannya kepada Pandu.

Di tengah perjalanan, Pandu, Kunthi, dan Madrim dihadang oleh Gendara dan Gendari. Mereka bermaksud merebut Kunthi dari tangan Pandu. Terjadilah perang. Gendara kalah. Sebagai pengakuan atas kekalahannya, Gendara menyerahkan Gendari, adiknya kepada Pandu. Pandu melanjutkan perjalanan pulang dengan ditemani tiga putri boyongan hasil perang dan sayembara yaitu Kunthi, Madrim, dan Gendari.

Di Astina, Pandu disambut gembira oleh semua kalangan, terutama Destarastra kakaknya. Demi ketaatannya kepada aturan bahwa seorang adik tidak diperkenankan menikah mendahuui kakaknya, diserahkannyalah ketiga putri boyongan tersebut pada kakaknya. Kakaknya disuruh memilih satu dari ketiga putri tersebut.

Destarastra memeriksa ketiga putri satu persatu. Giliran pertama adalah Kunthi. Setelah diraba, Destarastra menolak Kunthi menjadi istrinya karena mata batinnya tahu kalau Kunthi kelak hanya akan memiliki tiga anak. Giliran berikutnya adalah Madrim. Setelah memeriksanya, Madrim juga ditolak karena mata batinnya tahu kalau Madrim kelak hanya akan memiliki dua anak. Giliran ketiga, Gendari. Mata batin Destarastra tahu kalau Gendari kelak punya banyak anak, naka dipilihnya lah dia sebagai istrinya.

Dewi Gendari sangat kecewa saat dipilih oleh Destarastra. Ia sebetulnya sangat mengharapkan menjadi istri Pandu. Ia marah dan sakit hati. Ia mengutarakan tiga sumpah (tri ubaya). Pertama, sebagai rasa hormatnya kepada suaminya yang buta, ia rela menutup kedua matanya supaya tidak bias melihat keindahan dunia seperti yang dialami Destarastra. Kedua, ia akan berseteru selama-lamanya dengan Pandu karena dia telah mengecewkan hatinya. Ketiga, ia akan menumbuhkan rasa permusuhan antara anak Pandu dengan anaknya sendiri sampai berujung pada perang besar Barata Yudha.

\section{Tri Ubaya dalam Wahana Karawitan}

Cerita Kunthi dan Gendari tersebut saya alih wahanakan menjadi pertunjukan karawitan. Oleh karena pross alih wahana ini, ada beberapa perubahan disesuaikan dengan medium yang digunakan. Dalam pertunjukan wayang kulit, ada banyak medium yang digunakan. Setidaknya ada empat media yang digunakan dalam pertunjukan wayang, yaitu media rupa (boneka wayang), media tari (gerakan wayang), media musik (karawitan), media drama (penceritaan oleh dalang). Ketika dialihwahanakan menjadi satu media, yaitu media karawitan, maka urutan cerita dan tekanan cerita mengalami perubahan.

Penyajian Tri Ubaya dalam wahana Karawitan diwujudkan dalam delapan gending seperti berikut.

\section{Sayembara di Mandura}

Bagian ini menggambarkan situasi di kerajaan Madyantara saat Prabu Kurambadewa kedatangan tamu raja-raja dari Sewu negara yang ingin mengikuti satembara pilih di Mandura. Pada situasi ini disajikan gending garap balungan dan vokal yang berkarakter keras yang disisipi dengan lagu kanda serta lagu vokal balungan sebagai penggambaran dialog raja-raja Sewunegara.

\section{Keberangkatan Raja Sewunegara menuju Mandura.}

Bagianinimenggambarkansituasikeberangkatan raja-raja Sewunegara dari Madyantara menuju Mandura. Pada situasi ini disajikan gending budhalan lengkap dengan vokalnya yang diakhiri dengan gending Gilak Jawa.

\section{Kesedihan Narasoma}

Bagian ini menggambarkan situasi di tengah perjalanan saat Raden Narasoma sedang bersedih hati kemudian berangkat ke Mandura untuk mengikuti sayembara pilih. Pada situasi ini disajikan gending semacam ayak-ayak yang berkarakter sedih dan disisipi dengan monolog dan diteruskan dengan gending seperti playon. 


\section{Keindahan Mandura}

Bagian ini menggambarkan situasi di kerajaan Mandura yang tampak indah serta hangarbingarnya kerabat kerajaan saat mendirikan panggung sebagai ajang sayembara pilih. Pada situasi ini disajikan gending semacam ayakayak garap bedayan yang diaransemen ala musik Bali disisipi dengan lagu kanda dan situasi saat kedatangan raja-raja Sewunegara dari kerajaan Madyantara di Mandura. Pada situasi ini disajikan gending semacam sampak yang disisipi lagu Kanda yang menggambarkan tentang maksud dan tujuan raja-raja Sewunegara kepada raja Mandura, serta situasi saat pelaksanaan sayembara pilih. Pada situasi ini disajikan semacam pengumuman atau wara-wara, yakni pengumuman kepada semua peserta untuk mempersiapkan diri karena pelaksanaan sayembara akan dimulai. Setelah itu dilanjutkan dengan gending yang berkarakter agung yang disisipi dengan lagu Kanda.

\section{Pertemuan Narasoma, Gendari, dan Pandu}

Bagian ini menggambarkan situasi perjalanan saat Narasoma bersama Gendari ke Negara Mandaraka bertemu Pandu. Situasi ini disajikan tembang ada-ada yang sudah dimodivikasi dan gending baru dalam aransemen musik Sunda dan gending perang yang disisipi dengan lagu Kanda. Selain itu pada bagian ini juga dimaksudkan untuk menggambarkan situasi perjalanan saat Pandu bertemu Gendara dan Gendari. Pada situasi ini disajikan gending yang diaransemen seperti teknik tabuhan Jawa Timuran dan Bali yang disisipi dan diselingi dengan vokal dan lagu Kanda.

\section{Penantian Destarastra}

Bagian ini menggambarkan situasi saat Destarastra bersama keluarga kerajaan menanti datangnya Pandumengikutisayembara, sertasituasi pulangnya Pandu ke Astina dengan membawa tiga putri boyongan. Untuk mewujudkan suasana tersebut disajikan gending baru bernama Sranti yaitu gending semacam ayak-ayak garap bedayan yang disisipi aransemen Bali agar muncul suasana lain yang dapat menghias gending tersebut yang kemudian dirangkai dengan gending Gupuhgupuh. Selain itu juga ditampilkan sebuah lagu Kanda yang isi dan suasananya menggambarkan penyerahan tiga putri boyongan dari Pandu kepada Destarastra agar dipilih salah satu untuk dijadikan istrinya.

Gending Sranti Laras Pelog

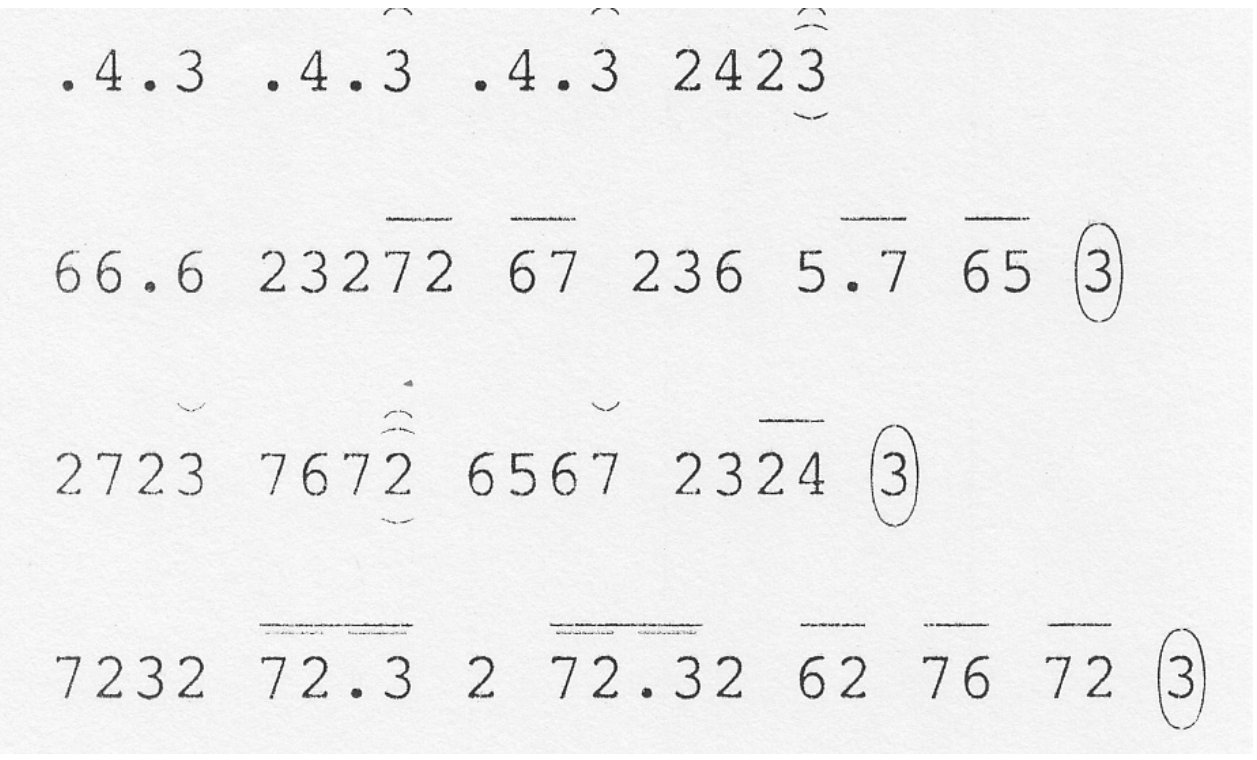


Aransemen Bali

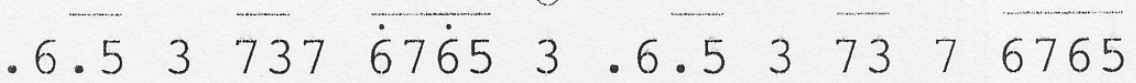

$$
\begin{aligned}
& \begin{array}{llllllllllllll}
.11 & .1 & 1 & 2.3 & 12 & 3 & 6.5 & 63 & 56 & 72 & 3 & 5
\end{array} \\
& 6567 \quad 653 \hat{\sigma} \quad 5327 \quad 672 \text { (3) } \\
& \ldots+\cdots, \ldots+\bar{r}+r \text { A }
\end{aligned}
$$

\section{Vokal Bedayan}

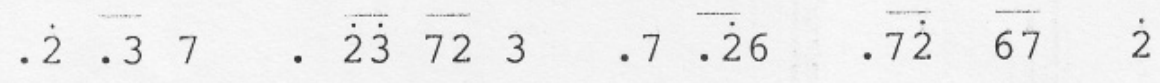

Wa-u ta nenggih punika minangka sambunging kanda
.$\overline{6.7} \quad 5$
$\overline{67} \overline{53} \quad 7$
. $\dot{2} \dot{3}$.
$\dot{2} \dot{3}$.

Kang a neng nagri Ngastina nenggih ri sang

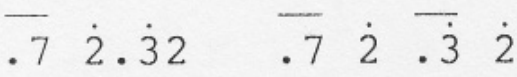

desta rastra ne ngga da teng

$.6 \dot{2} 7 \quad 6 \dot{7} \dot{2} 3$

Ing kang $\quad \mathrm{ra}-\mathrm{yi}$

$\begin{array}{lllllllll}.6 \overline{6} & 5 & . \overline{67} & \overline{56} & 7 & .6 & \overline{53} & \overline{56} & 3\end{array}$

Kang a-neng jro ning praja ne-nggih ri sang Des ta ras

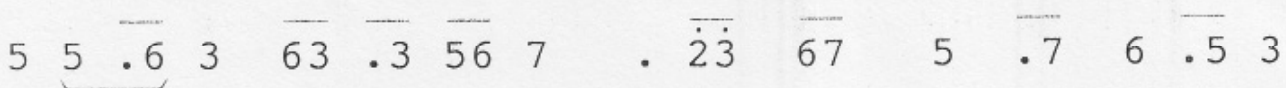

trasam pun sawe tawis dangu nengga kundure ingkang rayi

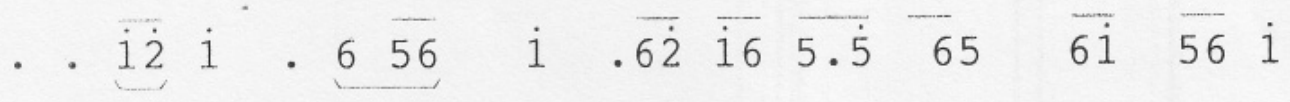
Raden $\quad \mathrm{Pa}-\quad$ ndu kang melu sayem mbaraning nagri Mandura

$\begin{array}{llllllllllll}\ldots \overline{1} & \overline{32} & \overline{\dot{2}} & \overline{3 \dot{2}} & 7 & \dot{32} & \overline{76} & 5 & 3 & 1 & \overline{25} & 3\end{array}$

Jroning batos a me muji mrih sembada ing kang ra yi 
Gending Gupuh-Gupuh

$$
\begin{aligned}
& .6 .73 .3 \pm \frac{7}{7} .6752 .23 \\
& .7 .3 \quad 3.3 \overline{7} \quad .675 \quad 3.3 \overline{5} \\
& .7 .6675(6) \cdot 3.5563 \overline{5} \\
& 7656666 \cdot 5 \cdot 3 \cdot 242
\end{aligned}
$$

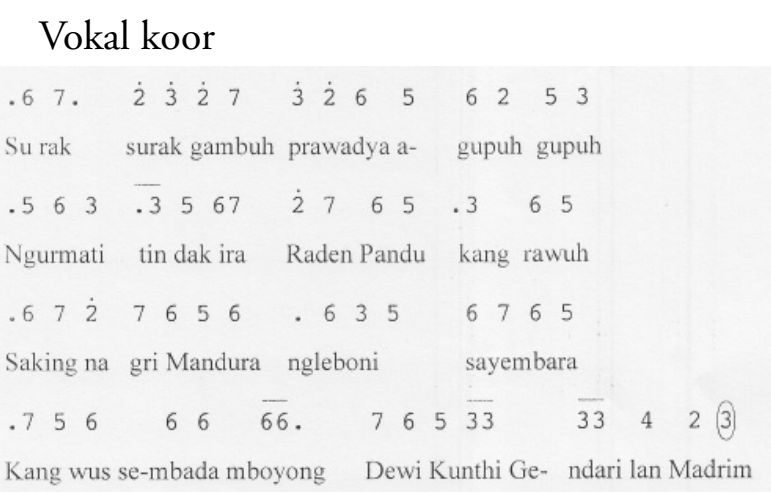

\section{Lagu Kanda}

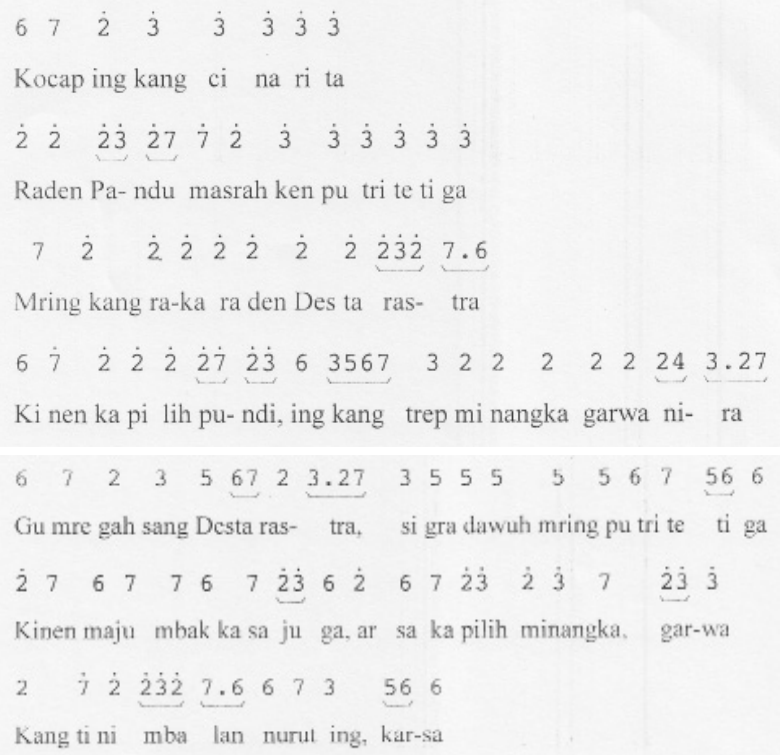

Penyajian dimulai dari gending Sranti yang disajikan satu kali putaran yang dirangkai dengan gending Gupuh-gupuh. Setelah satu putaran, volume gending ini diperkecil dan didisipi dengan vokal Gupuh-gupuh. Setelah vokal selesai volume gending dibesarkan kembali satu putaran kemudian dikecilkan lagi dan disisipi lagu Kanda hingga usai lalu disambung dengan lagu Pilihpilih.

\section{Destarastra memilih satu putri.}

Bagian ini menggambarkan situasi saat Destarastra memilih satu dari tiga putri boyongan untuk dijadikan istrinya dan situasi saat Gendari terkejut, sedih, dan marah ketika terpilih menjadi istri Destarastra. Pada situasi ini disajikan gending romantis dengan garap langgam yang dilanjutkan gending tegang, sedih, dan mencekam.

Untuk mewujudkan peristiwa dan suasana tersebut disajikan gending Pilih-pilih, sebuah gending yang saya buat. Gending ini bernuansa romantis. Gending ini berbentuk semacam langgam yang penyajiannya didahului dengan gending berirama keras sejenis gending Lancaran yang telah mengalami proses penggarapan baru. dirangkai dengan gending lain yang saya buat, yaitu gending Anjola. Gending ini dilengkapi dengan vokal. Setelah selesai gending Anjola dilanjutkan dengan gending Nguman-uman yang dilengkapi dengan vokal koor puteri Paseksen.

\section{Gending Pilih-pilih Laras Pelog}

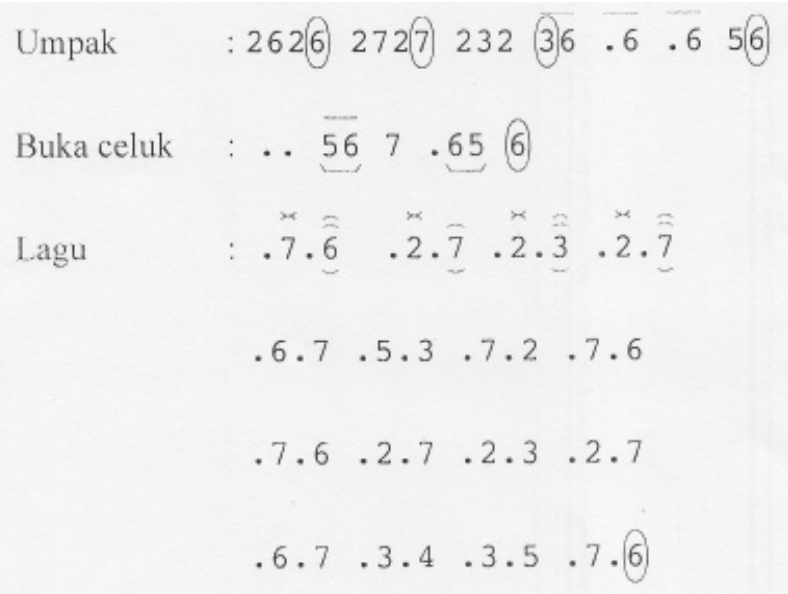


Vokal:

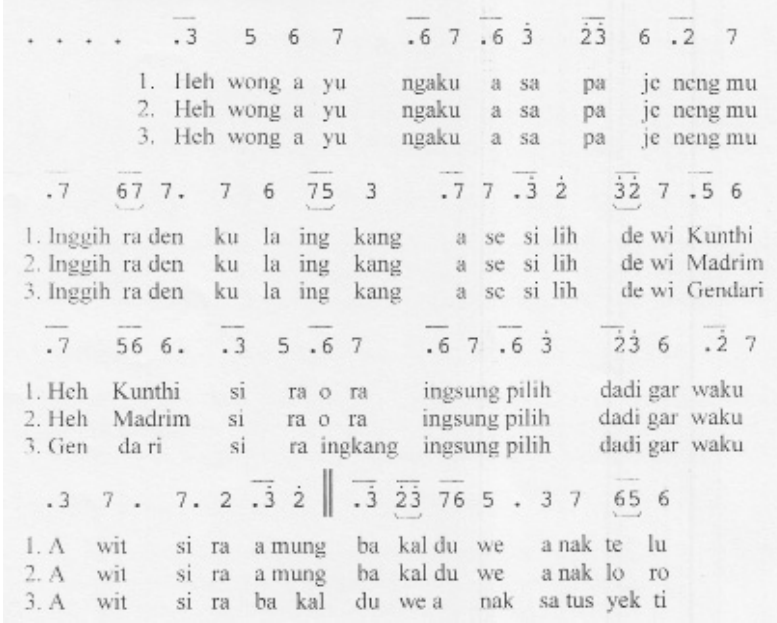

Gending Anjola (Aransemen Bali)

$$
\begin{aligned}
& \begin{array}{lllll}
.3 .6 & .7 & .5 & .3 .6 & .7 .2
\end{array} \\
& .3 .6 .7 .2 \cdot 3.6 \cdot 7 \cdot 2 \cdot 1 \\
& \|3232 \cdot 32323232323(2)\|
\end{aligned}
$$

Ada-ada Anjola

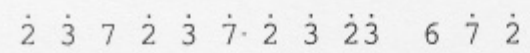

Njola anjola tyasira dewi Gendari

$$
\left.\begin{array}{lllllllllllll}
7 & 7 & 7 & 23 & 27 & 7 & 2 & 2 & 2 & 2 & 23 & 6 & 2
\end{array}\right]
$$

Gending Nguman-uman

Isian Balungan dan Bonang:

$$
\ldots \overline{12} \quad . \overline{32} \quad . \overline{12} \ldots \overline{123} \overline{5 \overline{35}}
$$

$\begin{array}{lll}656 & 7 & 32\end{array}$

Vokal:

$$
\begin{aligned}
& \ldots \overline{i \dot{2}} \cdot \overline{3 \dot{3}} \cdot \overline{i \dot{2}} \cdot \overline{.6} \overline{i \dot{2}} \overline{3 \dot{3}} \cdot \overline{2} \text { i } \overline{6 \dot{1}} \dot{2} \\
& \text { Pandu Pandu Pandu yekti ke parat heh sli ra- mu }
\end{aligned}
$$

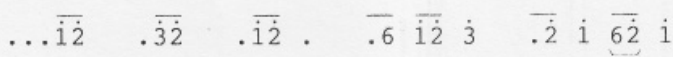

$$
\begin{aligned}
& \text { Pandu Pandu Pandu sira nyidra- ni jan ji- mu }
\end{aligned}
$$

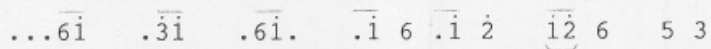

$$
\begin{aligned}
& \text { Pandu Pandu Pandu mula si-ra ha ywa kaget }
\end{aligned}
$$

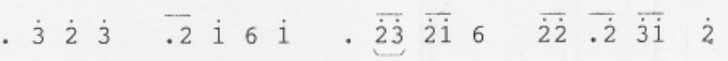

$$
\begin{aligned}
& \text { Lamun a- ku prajanji Tri Ubaya hehe ti tena na }
\end{aligned}
$$

Vokal Koor Puteri Paseksen

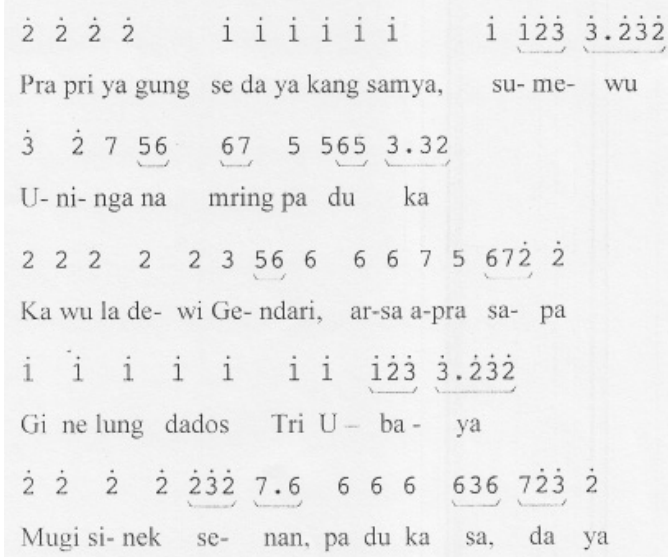

Penyajian gending-gending di atas diawali dari gending Pilih-pilih bagian Umpak disajikan dua kali. Setelah suwuk dilanjutkan koor buka celuk diikuti Gending Pilih-pilih. Gending ini disajikan tiga kali putaran; dua kali putaran dalam irama lancar dan satu kali putaran dalam nuansa langgam. Selesai gending ini dilanjutkan ke gending Anjola yang penyajiannya menggunakan teknik pukulan lamba ditampilkan dua kali putaran kemudian dilanjutkan teknik pukulan ngracik dengan alat pukul yang terbuat dari tanduk. Setelah beberapa kali putaran, gending ini disisipi dengan $A d a-$ ada Anjola hingga usai. Selesai Ada-ada Anjola dilanjutkan dengan gending Nguman-uman. Setelah beberapa putaran gending ini disisipi dengan vokal gending Nguman-uman dua kali putaran kemudian dirangkai dengan vokal koor puteri Paseksen hingga selesai.

\section{Tri Ubaya: Sumpah Gendari}

Bagian ini menggambarkan situasi saat Gendari bersumpah yang berisi tiga janji atau tri ubaya dihadapan kerabat kerajaan Astina. Pada situasi iji disajikan koor vocal putri yang menggambarkan permintan Gendari kepada semua kerabat kerajaan Astina agar memperhatikan dan mau menjadi saksi dari apa yang akan disumpahkan nanti. Di sini disajikan gending Ubaya yang disisipi lagu Tri Ubaya dan gending Horeg. Selain itu juga penggambaran situasi saat Dewi Gendari berpasrah diri kepada Tuhan apa yang akan terjadi pada dirinya.

Untuk menggambarkan suasana seperti di atas telah saya ciptakan beberapa gending. Pertama, 
gending Ubaya yang dirangkai dengan vokal koor puteri tembang Tri Ubaya. Setiap baris lagu tersebut ditirukan secara koor dengan menggunakan nada 6,3 , dan 2 oleh tiga vokalis pria. Ini dimaksudkan untuk mempertegas karakter dari tembang Tri Ubaya. Setelah sajian tersebut di atas usai kemudian disajikan teriakan dari semua musisi dengan kata-kata"Sineksen jagad sak isine" yang diteruskan dengan pukulan bebas dan keras dari semua instrumen bernama gending Horeg sebagai penggambaran suasana damai sedang bergoncang saat mendengarkan sumpah Gendari, seolah-olah dunia ini ikut menjadi saksi dari sumpah tersebut.

Gending Ubaya Laras Pelog

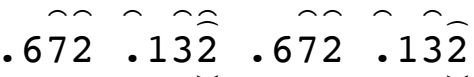

$$
\begin{aligned}
& \begin{array}{llllllllllll}
. \overline{7.6} & \overline{56} & 7 & . \overline{6.5} & \overline{35} & 6 & . \overline{33} & \overline{33} & 3 & 2 & \overline{22} & \overline{21}
\end{array}
\end{aligned}
$$

Ilustrasi:

$$
\left[\begin{array}{llll}
22222 & 222 \underline{2} & 2222 & 222(2):]
\end{array}\right.
$$

Tembang:

$$
\left.\begin{array}{llllllll}
2 & 2 & 6 & 7 & 2 & \rightarrow & \text { koor putri } \\
6 & 6 & 3 & 5 & 6 & \rightarrow \text { koor putra }
\end{array}\right\} \text { koor bersama }
$$

1. Kang se- pi- san

2. Kang ka- pi- ndo

3. Kang ka- te- lu

$$
\begin{array}{lllllllll}
2 & \dot{2} & 2 & \dot{2} & \dot{2} & \dot{3} & \dot{4} & \dot{3} \dot{4} & \dot{3}
\end{array}
$$

1. Mi-nang ka se- tya ku marang, gar- wa

2. A- wit Pa-ndu nyi dra ni mring ja- nji

3. Ga ndeng Pa ndu i- ku sa-tru yek- ti

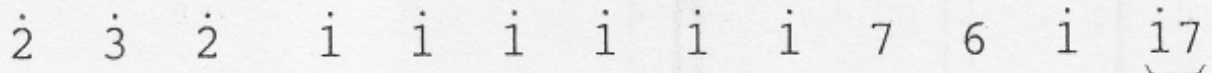

1. Di-men imbang den nya tan wruh en da hing ja-gad

2. Kang wus ga we la- ra lan ku- ci wa ning ma-nah

3. Lan sun a nggep mi-nang ka da- di mungsuh ing wang

$$
\begin{array}{llllllllllllllll}
3 & \dot{2} & 6 & 7 & \dot{2} & \dot{2} & \dot{2} & \dot{2} & \dot{2} & \dot{2} & \dot{1} & \dot{2} & \dot{3} & 6 & 7 & \dot{3}
\end{array}
$$

1. Ingsun ar-sa nutup dwi ne- tra ka wu la se la mi nya

2. Mu la ing sun a-nga nggep Pandu minang ka satru a-gung

3. Ingsun arsa ndeder pe rang putra ku klan wan tu-run-mu 


\section{Tembang Pasrah}

Vokal koor putra

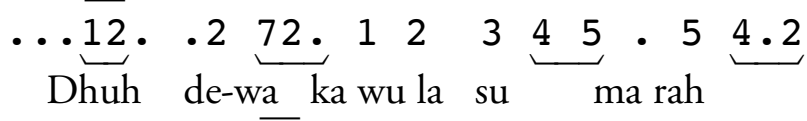

$\begin{array}{llllllllll}\ldots 6.6 & 56 & \underbrace{7 .}_{\text {Mring ker sapa }} & 27 & 5 & .2 & 2 & \underbrace{13} & 2\end{array}$

Vokal koor putri

$$
\begin{aligned}
& . \dot{2} \cdot \overline{\dot{2} \dot{1}} \dot{2} . \overline{\dot{3} \dot{1}} \dot{2} \cdot \dot{3} \quad \dot{4} \cdot \dot{3}_{\overline{2}} 4 \quad \ldots \dot{5} \cdot \dot{2} \\
& \text { Dhuh a dhuh Jawa ta A gung ing kang ma ha } \\
& \begin{array}{lllllllllllllll} 
& \ldots & 72 & 7 & 5 & 2 & \ldots & 12 & 12 & 12 & 34 & 5 \ldots 4 & 2
\end{array} \\
& \text { Welas lan a sih ka wu la mung pas rah } \\
& \begin{array}{lllllllllllll}
.242 & .2 & 1 & 3 & 2 & . & \dot{2} & . \dot{2} & . & \text { i } & \dot{2} & \dot{3} & \dot{2}
\end{array} \\
& \mathrm{Om} \text { a wi ge nam mas tu na ma si dham. }
\end{aligned}
$$

Penyajian dimulai dari gending Tri Ubaya satu kali putaran kemudian dirangkai dengan ilustrasi yang disisipi tembang Tri Ubaya disajikan tiga kali putaran dengan syair lagu yang berbeda, yakni pada tampilan pertama semua syair lagu menggunakan syair lagu yang di sebelah kirinya ada tanda angka 1. Tampilan kedua menggunakan syair lagu yang di sebelah kiri ada angka 2, dan tampilan yang ketiga menggunakan syair lagu yang disebelah kirinya ada angka 3. Setelah tembang Tri Ubaya selesai kemudian dirangkai dengan teriakan semua musisi dengan suara bebas dan keras dengan kata-kata "sineksen jagat saisine". Setelah itu dilanjutkan dengan pukulan bebas dan keras menggunakan nada-nada baik yang terdapat pada gamelan sekaten maupun gamelan Ageng dalam waktu sesaat yang kemudian dilanjutkan ke tembang Pasrah. Penyajian tembang Pasrah diawali dengan pukulan kethuk secara pelanpelan. Tembang Pasrah ini terdiri dari dua macam tembang, yaitu vokal koor putera diikuti vokal koor puteri hingga selesai.

\section{Penutup}

Alih wahana berupa komposisi karawitan Tri Ubaya ini terwujud melalui proses yang panjang dan bertahap yang berawal dari adanya ide atau gagasan, konsep tema, dan penuangan. Ide untuk menciptakan ini muncul karena adanya rangsang awal saya sebagai musisi karawitan wayang dan dalang yang sangat mengagumi pergelaran wayang lakon Alap-alapan Kunthi atau Sayembara Kunthi.

Karya ini bisa terwujud karena adanya kreatifitas yang mengacu pada metode penciptaan Alma M. Haw Kins antara lain eksplorasi, improvisasi, dan pembentukan. Tentu saja saya dapat mengerjakan ini karena menguasai teknik karawitan antara lain gêmbyang, kêmpyung, ngècèk, ngênyut, dan lain sebagainya.

Karya seni Tri Ubaya ini merupakan salah satu bentuk kreatifitas musikal yang mengolah perangkat gamelan sekaten dan agêng menjadi bentuk pertunjukan yang tidak lagi menempatkan keberadaannya sebagai pengiring akan tetapi lebih berperan sebagai media utama pertunjukan mandiri yang dapat menerjemahkan suatu tokoh, suasana, karakter, dan peristiwa dalam cerita wayang yang pada umumnya dilakukan oleh seorang dalang.

Alih wahana ini juga merupakan upaya penulis untuk mengembangkan karawitan sekaten dan karawitan gamlan agêng yang penggarapan ritme, tempo, melodi, dan dinamika keluar dari pola-pola tradisional yang sudah ada, dilengkapi dengan penggarapan aspek-aspek pertunjukan yang lain sepeti tata panggung, seting instrumen, tata cahaya dan busana yang dapat menghasilkan suatu pertunjukan karawitan yang lebih inovatif. 


\section{Kepustakaan}

Damono, Sapardi Djoko. 2012. Alih Wana. Jakarta: Editum

Hastanto, Sri. 1991. "Karawitan: Serba-serbi karya Ciptaannya” dalam Jurnal Seni Vol. 1. No. 1, 1991.

Hawkins, Alma. 2003. Bergerak Menurut Kata Hati: Metoda Baru Dalam Menciptakan Tari. Jakarta: masyarakat Seni Pertunjukan Indonesia.

M Prier, Karl-Edmund. 1996. Ilmu Bentuk Analisis Musik. Yogyakarta: Pusat Musik Liturgi.
Patmosoekotjo, S. 1990. Sisilah Wayang Purwa Mawa Carita. Surabaya: Citra Jaya Murti.

\section{Audio-Video}

Nartosabdho, Ki. 1984. Alap-alapan Kunthi (Pita Casset). Semarang: Kusuma Record.

1985. Semar Mbarang Jantur (Pita Casset). Semarang: Dahlia Record.

Suyoto. 1997. Gendhing Sekaten Kraton Yogyakarta (Pita Casset). Koleksi pribadi. 